\title{
Perfusion of isolated human placenta
}

\author{
BY K. R. PAGE \\ University of Aberdeen, School of Biomedical Sciences, Physiology Division, Marischal College, \\ Aberdeen AB9 1AS
}

Tissue culture and membrane vesicle studies provide well-defined in vitro models of trophoblast function but do not preserve the anatomical arrangement of placental components or the discreteness of the maternal and fetal blood circulations within the placenta. The exchange surfaces facing each of these blood-streams have different properties which generate the polarity associated with both placental transport and endocrine functions. In vitro perfusion of the human placenta offers a model which preserves the integrity of the two blood circulations and so is especially suited to studies of this polarity.

Particularly important problems relating to the in vitro perfusion of the placenta are:

(1) the delay between delivery and perfusion;

(2) the absence of maternal blood vessels capable of cannulation;

(3) the large size of the organ and its blood supplies.

The latter two problems have been largely overcome by a technique devised by Panigel (1968). This makes use of the fact that the placenta has a lobular organization of blood circulation. Consequently, it is possible to dually perfuse a single lobule, (size varying from about 10 to $60 \mathrm{~g}$ ), rather than the entire placenta. Fetal circulation is maintained via cannulas inserted into the branches of the umbilical artery and vein which supply the lobule. The maternal circulation is supplied by blunt glass cannulas (normally two or four) inserted deep into the intervillous space of the lobule.

Many workers follow the original protocol of Panigel (1986) in placing the placenta in a temperature-controlled chamber with its maternal surface uppermost. In the author's laboratory, however, an arrangement where the maternal aspect faces downwards has been chosen. This greatly speeds up the time-period required to mount the tissue, and minimizes dead-space problems in the maternal circuit. It is particularly well suited for high-speed sampling protocols such as the paired-tracer dilution technique (Sweiry et al. 1986).

In the author's laboratory perfusates used are either Krebs Ringer or Culture Medium 199. Perfusate $\mathrm{pH}$ is kept between $7 \cdot 2$ and 7.4. Dextran or bovine serum albumin act as plasma expanders, and oxygen-carbon dioxide $(95: 5, \mathrm{v} / \mathrm{v})$ is used to gas the perfusates. Although oxygenation of both solutions is normally used, oxygenation of the maternal side alone markedly delays the onset of capillary filtration i.e. leakage of plasma from fetal to maternal circulation (Miller et al. 1985). Viability is checked by the absence of capillary filtration and preservation of low $(<80 \mathrm{~mm} \mathrm{Hg})$ fetal inflow pressures. Typically inflow rates of $6 \mathrm{ml} / \mathrm{min}$ are employed on the fetal side and $20 \mathrm{ml} / \mathrm{min}$ on the maternal side. As further checks on viability, $\mathrm{O}_{2}$ and glucose consumptions are routinely measured, $\mathrm{O}_{2}$ consumptions ranging from 0.27 to $0.41 \mu \mathrm{mol} / \mathrm{min}$ per $\mathrm{g}$ wet weight and glucose consumptions from $0 \cdot 19$ to $0 \cdot 29 \mu \mathrm{mol} / \mathrm{min}$ per g wet weight.

Histological and ultrastructural studies have been conducted on placentas following 3 $\mathrm{h}$ of perfusion. Light microscopy showed villous profiles that appeared normal in terms 
of overall numerical density, size and outline. The thickness of syncytiotrophoblast appeared to be normal and there were no signs of any exaggerated aggregation of syncytial nuclei or abnormal signs of nuclear pyknosis. The overall appearance of the tissue using electron microscopy was satisfactory, mitochondrial profiles within the syncytium being normal in terms of their sizes and electron density. Profiles of rough and smooth endoplasmic reticulum were normal with only occasional cisternal dilation and vesiculation. The microvillous border showed no indication of loss of organelle number.

Anatomically the perfused lobule is ideally suited for studying transport between maternal and fetal circulations. However, some substrates present problems that complicate its use in this way. It is not possible to obtain a uniform perfusion of the entire volume of lobular tissue (Barker et al. 1987). This complicates kinetic analysis of the movement of large molecules such as pregnancy-related proteins, although it is clear that synthesis and release of these proteins into the maternal (but not fetal) circulations continues in the perfused lobule (Bersinger et al. 1989; Page et al. 1989). The study of small molecules such as mineral ions is hampered by the presence of significant shunt pathways across the tissue (Stulc et al. 1989). Direct study of the active component of the movement of calcium from maternal to fetal circulations using steady-state fluxes of ${ }^{45} \mathrm{Ca}$ is, therefore, complicated by the presence of a large passive flow of isotope. However, this does not prevent detection of changes in $\mathrm{Ca}$ flux induced by a metabolic inhibitor (Abramovich et al. 1987; Stulc et al. 1989).

As an alternative approach we have examined the differential uptake or release of minerals at each placental surface. With this approach, it is possible to demonstrate the active nature of $\mathrm{Ca}$ transport across the placenta via an ATPase located predominantly in the basal (fetal facing) membrane of the trophoblast (Williams et al. 1990a). The author has also utilized a similar method to demonstrate that transplacental zinc movements across the lobule are probably rate-controlled at the maternal border of the placenta (Page et al. 1988). Another approach to the study of ion transport processes involves the paired-tracer dilution technique (Sweiry et al. 1986). This has shown specific transport systems for choline as well as $\mathrm{Ca}$ on both sides of the syncytiotrophoblast.

Most recently we have observed that the 1-34 segment of bovine parathyroid hormone stimulates the production of the second messenger cyclic AMP in the perfused lobule. This has involved the use of dual-dual perfusions (Williams et al. 1990b). We are now examining the 'sidedness' of the action of this hormone as well as investigating any effects it may have on ion transport.

In conclusion, the dually-perfused human placental lobule is an in vitro model well suited for the study of vectorial processes such as solute transport and hormone action. It is one in a range of in vitro techniques, each of which has its own special contribution to make, and which, when taken collectively, are making a significant contribution to our understanding of human placental function.

Support by Action Research for the Crippled Child and the Sir Jules Thorn Charitable Trust is gratefully acknowledged.

\section{REFERENCES}

Abramovich, D. R., Dacke, C. G., Elcock, C. \& Page, K. R. (1987). Effect of dinitrophenol on calcium transfer across the dually perfused human placental lobule. Journal of Physiology 386, 21P. 
Barker, G., Boyd, R. D. H., Lear, G. H. \& Sibley, C. P. (1987). Incomplete perfusion of the in vitro isolated human placental lobule. Journal of Physiology 394, $168 \mathrm{P}$.

Bersinger, N. A., Malek, A. \& Schneider, H. (1989). De novo synthesis of pregnancy specific and pregnancy associated proteins by the in vitro perfused human term placenta. In Placenta as a Model and a Source, pp. 51-62 [O. Genbačev, A. Klopper and R. Beaconsfield, editors]. Nèw York: Plenum Press.

Miller, R. K., Wier, P. J., Maulic, D. \& di Sant'Agnese, P. A. (1985). Human placenta in vitro: Characterisation during $12 \mathrm{~h}$ of dual perfusion. In In vitro Perfusion of Human Placental Tissue, Contributions to Gynecology and Obstetrics, vol. 13, pp. 77-84 [H. Schneider and J. Dancis, editors]. Basel: Karger.

Page, K. R., Abramovich, D. R., Aggett, P., Todd, A. \& Dacke, C. G. (1988). The transfer of zinc across the term dually perfused human placental lobule. Quarterly Journal of Experimental Physiology 73, 585-593.

Page, K. R., Abramovich, D. R., Dacke, C. G., Henderson, K. \& Klopper, A. (1989). Protein release by the in vitro human placental lobule when dually perfused by different protocols. In Placenta as a Model and a Source, pp. 15-25 [O. Genbačev, A. Klopper and R. Beaconsfield, editors]. New York: Plenum Press.

Panigel, M. (1968). Placental perfusion. In Fetal Homeostasis, vol. 4, pp. 15-25 [G. Wynn, editor]. New York: Appleton-Century-Crofts.

Stulc, J., Stulcova, B., Svihovec, J. \& Brestak, M. (1989). Transcellular transport of Ca across the perfused human placental lobule. Placenta 10, 475.

Sweiry, J. H., Page, K. R., Dacke, C. G., Abramovich, D. R. \& Yudilevich, D. L. (1986). Evidence for saturable uptake mechanisms at maternal and fetal sides of the perfused human placenta by rapid paired-tracer dilution: Studies with calcium and choline. Journal of Developmental Physiology 8, 435-446.

Williams, J. M. A., Abramovich, D. R., Dacke, C. G., Mayhew, T. M. \& Page, K. R. (1990). Raised cAMP levels in human placental homogenates after treatment with Forskolin, bPTH(1-34) and IBMX. Bone 11, 377.

Williams, J. M. A., Abramovich, D. R, Dacke, C. G., Mayhew, T. M. \& Page, K. R. (1991). Inhibitor action on placental calcium transport. Calcified Tissue International 48, 7-12. 